\title{
Synthesis of Intermetallics in Fe-Al-Si System by Mechanical Alloying
}

\author{
Kateřina Nová ${ }^{1, *}$, Pavel Novák ${ }^{1}$, Filip Pri̊ša ${ }^{1}$, Jaromír Kopeček ${ }^{2}$ id and Jaroslav Čech ${ }^{3}$ \\ 1 Department of Metals and Corrosion Engineering, University of Chemistry and Technology, \\ 16628 Prague, Czech Republic; panovak@vscht.cz (P.N.); prusaf@vscht.cz (F.P.) \\ 2 Institute of Physics of the Czech Academy of Sciences, 18221 Prague, Czech Republic; kopecek@fzu.cz \\ 3 Department of Materials, Faculty of Nuclear Sciences and Physical Engineering, \\ Czech Technical University in Prague, 12000 Prague, Czech Republic; Jaroslav.Cech@fjfi.cvut.cz \\ * Correspondence: novakx@vscht.cz; Tel.: +42-022-044-4055
}

Received: 22 October 2018; Accepted: 19 December 2018; Published: 25 December 2018

check for updates

\begin{abstract}
Fe-Al-Si alloys have been recently developed in order to obtain excellent high-temperature mechanical properties and oxidation resistance. However, their production by conventional metallurgical processes is problematic. In this work, an innovative processing method, based on ultra-high energy mechanical alloying, has been tested for the preparation of these alloys. It has been found that the powders of low-silicon alloys (up to $10 \mathrm{wt}$. \%) consist of FeAl phase supersaturated by $\mathrm{Si}$ after mechanical alloying. $\mathrm{Fe}_{2} \mathrm{Al}_{5}$ phase forms as a transient phase at the initial stage of mechanical alloying. The alloy containing $20 \mathrm{wt}$. \% of $\mathrm{Si}$ and $20 \mathrm{wt}$. \% of $\mathrm{Al}$ is composed mostly of iron silicides $\left(\mathrm{Fe}_{3} \mathrm{Si}\right.$ and $\left.\mathrm{FeSi}\right)$ and FeAl ordered phase. Thermal stability of the mechanically alloyed powders was studied in order to predict the sintering behavior during possible compaction via spark plasma sintering or other methods. The formation of $\mathrm{Fe}_{2} \mathrm{Al}_{5}$ phase and $\mathrm{Fe}_{3} \mathrm{Si}$ or $\mathrm{Fe}_{2} \mathrm{Al}_{3} \mathrm{Si}_{3}$ phases was detected after annealing depending on the alloy composition. It implies that the powders after mechanical alloying are in a metastable state; therefore, chemical reactions can be expected in the powders during sintering.
\end{abstract}

Keywords: powder metallurgy; intermetallics; mechanical alloying; iron aluminide; iron silicide

\section{Introduction}

Over the past few years, materials based on intermetallic compounds are increasingly used thanks to their wide range of properties. For example, shape memory alloys (e.g., NiTi) are very attractive, as well as materials for high-temperature use, such as $\mathrm{NiAl}$ or TiAl. Other examples are FeAl or $\mathrm{Fe}_{3} \mathrm{Al}$ intermetallics, which are used in strongly oxidizing or sulphidizing environments in combination with high temperatures [1-4]. Intermetallic compounds based on Fe-Al are considered to be very promising materials for industrial applications due to their low cost and high specific strength combined with excellent creep resistance, as well as their oxidation resistance at high temperatures $[2,5,6]$.

Fe-Al-Si system is of high interest because iron is the most common impurity in Al alloys, while $\mathrm{Si}$ is used as an alloying element [7]. Impurities come to Al mainly during recycling, when some iron-containing material cannot be magnetically separated from Al completely [8]. Within cast Al-Si alloys, Fe and Si form hard and brittle ternary phases, which influence corrosion and wear resistance [7]. One author's previous work [4] showed that the Fe-Al-Si phases need not be considered as detrimental phases in $\mathrm{Al}$ alloys, but can instead be used for advantages in high-temperature service, because the addition of Si to binary Fe-Al system improves oxidation resistance and thermal stability [9,10]. Based on this fact, a completely new grade of Fe-Al-Si alloys has been developed at UCT Prague during the 
past few years. The Fe-Al-Si alloy containing 20 wt. $\%$ of $\mathrm{Al}$ and $20 \mathrm{wt}$. $\%$ of $\mathrm{Si}$ was determined to be the most oxidation-resistant composition [10].

While the attractive properties of Fe-Al and Fe-Al-Si alloys are becoming increasingly evident, the technology is still insufficient to process them reliably and efficiently in order to maximize their mechanical properties. The already tested or practically applied methods include wire-arc additive manufacturing [11], air/vacuum induction melting [12], electroslag remelting [13], and hot pressing [14,15]. Mechanical alloying (MA) is a promising route for preparation of $\mathrm{Fe}-\mathrm{Al}$ and $\mathrm{Fe}-\mathrm{Al}-\mathrm{Si}$ alloys. The preparation via MA, usually carried out as high-energy ball milling, is a powder processing technique that allows the preparation of alloys with the final phase composition starting from blended elemental powder mixtures. The MA leads to the reduction of the input powder size thanks to the high kinetic energy of the milling balls. Furthermore, other phenomena also occur during the process, such as local welding of particles by plastic deformation, friction forces and diffusion, structure refinement due to severe plastic deformation, as well as the formation of solid solutions and chemical compounds (intermetallics) [16,17]. Products prepared by MA under appropriate conditions usually possess an ultrafine-grained nanocrystalline or amorphous microstructure [18]. Since grain size reduction often improves physical and mechanical properties in many cases, the nanocrystalline materials are very attractive for many applications. The nanocrystalline structure may result in higher hardness, strength or even ductility of brittle materials which results in better ductility of intermetallics [15]. Recently, we have developed an innovative MA process of ultra-high energy mechanical alloying [19]. Our development is based on the following facts:

1. A high ball-to-powder ratio (50:1-70:1) in combination with the use of large balls (20 $\mathrm{mm}$ in diameter) transfers very high kinetic energy to the powder even when moderate rotational velocity (400-600 rpm) is applied.

2. The use of any lubricant lowers the friction forces and temperature of the powder correspondingly. The reactions, which lead to the formation of intermetallics from elemental metals, are thermally activated in all cases. It implies that the use of any lubricant has to be avoided in ultra-high energy mechanical alloying, as was proved in reference [19].

This means that the ultra-high energy mechanical alloying process combines the advantages of mechanical alloying and self-propagating high-temperature synthesis, where the intermetallics are prepared by thermal activation. During this process we are able to produce intermetallics in $2-4 \mathrm{~h} \mathrm{[19].} \mathrm{This} \mathrm{is} \mathrm{more} \mathrm{rapid} \mathrm{than} \mathrm{the} \mathrm{milling} \mathrm{times} \mathrm{needed} \mathrm{with} \mathrm{other} \mathrm{processing} \mathrm{parameters} \mathrm{reported}$ in the literature to achieve similar phase composition and microstructure [20-23]. The above defined ultra-high energy mechanical alloying process is more efficient than the use of dedicated high-energy milling devices using 1200-2000 rpm [19].

For the estimation of the energy supplied to the powder during the milling process we can use the following statements: When the energy in mechanical alloying process is calculated, only the kinetic energy of the balls is taken into account. The energy caused by each collision in conventional mechanical alloying processes was calculated to be $10-400 \mathrm{~J} / \mathrm{hit}$ or $0.01-0.8 \mathrm{~W} / \mathrm{g}$ of the balls, depending on the degree of filling (or ball-to powder ratio) and rotational velocity [24-26]. This leads to the generation of the total energy of approx. $200 \mathrm{~W}$ in the case of our milling device operated under standard conditions. This could lead to the increase of temperature to approx. $300{ }^{\circ} \mathrm{C}$ [26].

However, in our milling process we don't avoid friction, as we apply a low amount of powder and use no lubricant. There are studies which show that some intermetallics can be generated in the friction mode only [27], because the generated temperature is a key factor for the formation of intermetallics. From our previous results with our ultra-high energy mechanical alloying process, we can conclude that the temperature localized in the contact point between powder, ball and wall exceeds $650{ }^{\circ} \mathrm{C}$, because this temperature is needed for the formation of some intermetallics as the $\mathrm{Ni}-\mathrm{Ti}$ and Fe-Al binary phases prepared in our previous paper [19]. The required temperature was determined by DTA heating curve of the powder mixtures of pure metals previously [16]. Hence it can 
be expected that the energy level including friction and the use of high ball-to-powder ratio is much more than two times higher (approx. 400-500 W). Current high speed mills reach the estimated energy usage of approx. $400 \mathrm{~W}$ [24].

Recently, there were published several studies about the application of conventional mechanical alloying in Fe-Al binary system. Krasnowski et al. [21], in their paper on Fe- 50 at. \% Al, described changes in the phase composition of the mechanically alloyed powder, and consequently the influence of the milling time on the crystallite size, the lattice strain and the lattice parameter. Also, Haghighi et al. [22] studied the mentioned system and the grain size as well as the lattice parameter depending on the milling time. Both teams, though working with different milling conditions, observed the same trend that the powder particle size increased at the initial stage, but then it began to decrease and in the end it remained constant. The reason for the decrease of the particle size is the deformation strengthening, which causes the increase of the strength and the decrease of plasticity, as well as the formation of intermetallics, which substantially increase brittleness.

This work aims to optimize conditions of innovative ultra-high energy mechanical alloying process for the preparation of Fe-Al-Si alloys and to describe the chemical processes during the mechanical alloying of these alloys in dependence on the content of Al and Si. The thermal stability of the powders after mechanical alloying is described in order to predict the sintering behavior.

\section{Materials and Methods}

The powder mixtures for milling were Fe-35 wt. \% Al-5 wt. \% Si; Fe-30 wt. \% Al-10 wt. \% Si and Fe-20 wt. \% Al-20 wt. \% Si. They are referred below as FeAl35Si5, FeAl30Si10 and FeAl20Si20, respectively. Elemental powders (Fe-purity of 99.7\%, Al-99.7\% and Si-99.5\%) were inserted in a milling jar together with milling balls both made of AISI 420 stainless steel, sealed and milled under a protective argon atmosphere to prevent oxidation during the process. The MA was carried out in a planetary ball mill (PM 100, Retsch, Haan, Germany) under the following conditions:

- duration: 0.5-6 h,

- each $30 \mathrm{~min}$ change of rotation direction,

- rotational velocity: $400 \mathrm{~min}^{-1}$,

- $\quad$ atmosphere: argon (purity of $99.996 \%$ )

- $\quad$ powder batch: $5 \mathrm{~g}$

- ball-to-powder weight ratio: 60:1.

The phase composition of milled powders was examined by X-ray diffraction (XRD) analysis (X'Pert Pro diffractometer, PANalytical, Almelo, Netherlands) using $\mathrm{CuK} \alpha$ radiation with the wavelength of $0.154060 \mathrm{~nm}$. The weight percentage of phases in milled powders and their crystallite sizes were calculated from the XRD data using the Rietveld method. Measurement error of the determination of weight percentage of individual phases by the used technique is $\pm 1-2 \mathrm{wt}$ \%. Metallographic samples were prepared from selected powders after mechanical alloying. Microstructures of powders were examined by VEGA 3 LMU (TESCAN, Brno, Czech Republic) scanning electron microscope after etching by modified Kroll's reagent (10 $\mathrm{mL} \mathrm{HNO}_{3}, 5 \mathrm{~mL} \mathrm{HF}, 85 \mathrm{ml} \mathrm{H} 2 \mathrm{O}$ ).

In order to predict the sintering behavior of the mechanical alloying products, all powders were subject to differential thermal analysis (DTA) using the Setaram Setsys Evolution device during heating in argon atmosphere by a rate of $30 \mathrm{~K} / \mathrm{min}$. Based on the results of this analysis, powders of all alloys were annealed at 630 and $1030{ }^{\circ} \mathrm{C}$ in an argon atmosphere and then subjected to XRD in order to determine the changes of the phase composition during the thermal exposure.

\section{Results and Discussion}

In the case of FeAl32 binary alloy, the mechanical alloying led to the temporary formation of $\mathrm{FeAl}_{3}$ phase after $0.5 \mathrm{~h}$ of milling [28]. This phase, as well as $\mathrm{Fe}_{2} \mathrm{Al}_{5}$ are known as transient phases formed by $\mathrm{Fe}+\mathrm{Al}$ reaction in reactive sintering synthesis of FeAl phase [29]. It was then converted to FeAl 
ordered phase (B2 structure) by the reaction with iron and only the FeAl phase was detected after $1 \mathrm{~h}$ of milling. Further prolongation of the milling did not cause any changes in the phase composition [28].

The addition of Si slowed down the phase development. After one hour of milling, there were still detectable amounts of $\mathrm{Al}$ and $\mathrm{Si}$ in the FeAl35Si5 alloy, see Figure 1 and Table 1 . The mechanical alloying for this powder mixture started by the formation of $\mathrm{Fe}_{2} \mathrm{Al}_{5}$ phase, as can be seen in the XRD pattern acquired after milling for $0.5-2 \mathrm{~h}$. This phase formed instead of $\mathrm{FeAl}_{3}$, probably due to the lower ratio of $\mathrm{Al}$ to $\mathrm{Fe}$ in FeAl35Si5 than in the FeAl32 alloy. It also could have happened due to the fact that the presence of silicon extending the region of stability of the $\mathrm{Fe}_{2} \mathrm{Al}_{5}$ phase, as presented in the Fe-Al-Si phase diagram [30]. The single-phase FeAl alloy is obtained after milling for $6 \mathrm{~h}$ (Figure 1 and Table 1).

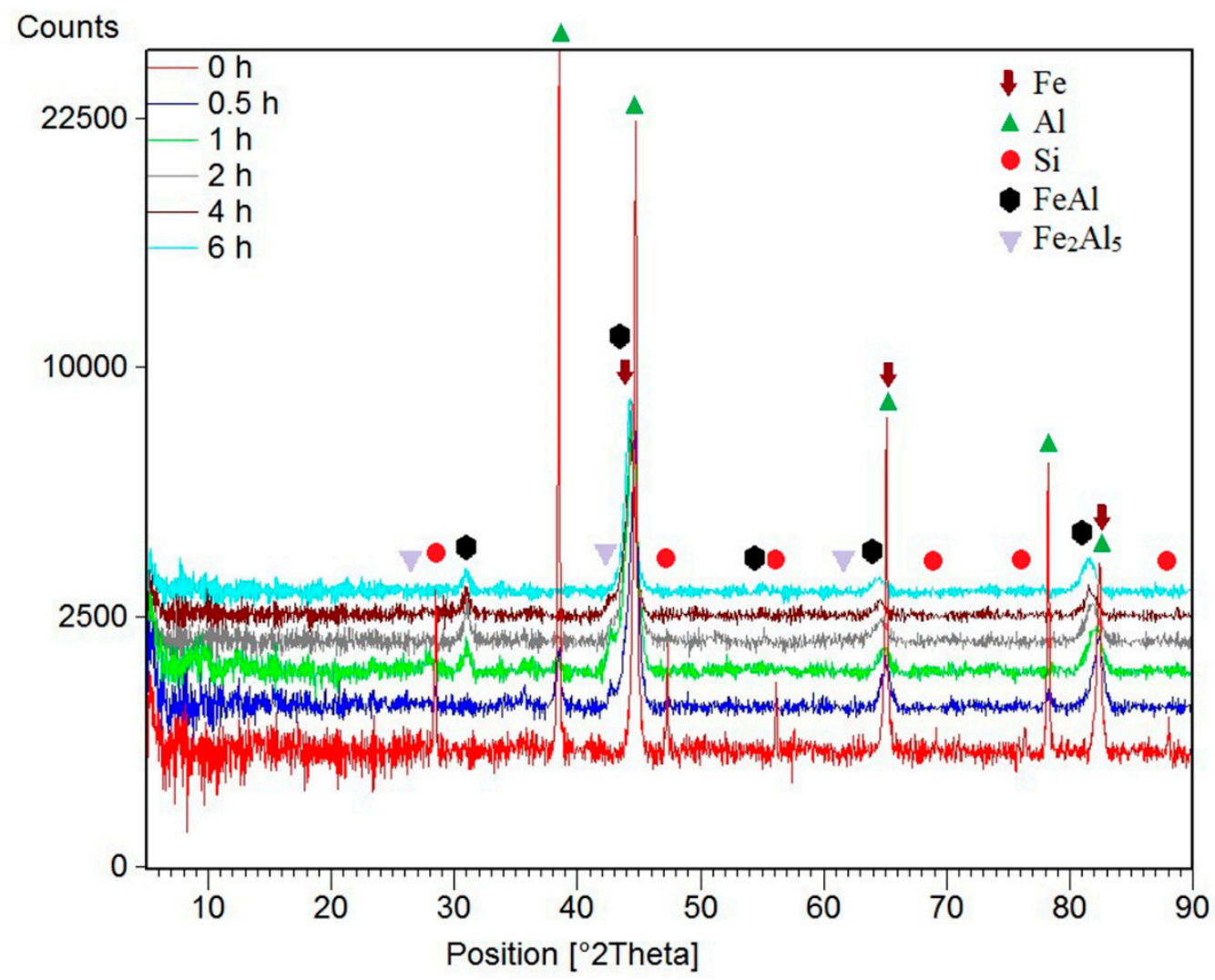

Figure 1. Phase composition of FeAl35Si5 alloy vs. milling time.

Table 1. Phase composition vs. milling time for FeAl35Si5 alloy.

\begin{tabular}{cccccc}
\hline \multirow{2}{*}{ Milling Time (h) } & \multicolumn{5}{c}{ Weight Percentage (\%) } \\
\cline { 2 - 6 } & $\mathbf{F e}$ & $\mathbf{A l}$ & $\mathbf{S i}$ & $\mathbf{F e A l}$ & $\mathbf{F e}_{\mathbf{2}} \mathbf{A l}_{\mathbf{5}}$ \\
\hline Before MA & 60 & 35 & 5 & 0 & 0 \\
0.5 & 55 & 31 & 5 & 0 & 9 \\
1 & 0 & 5 & 1 & 82 & 12 \\
2 & 0 & 0 & 0 & 94 & 6 \\
4 & 0 & 0 & 0 & 96 & 4 \\
6 & 0 & 0 & 0 & 100 & 0 \\
\hline
\end{tabular}

At the initial stage of milling of FeAl30Si10 powder blend, only the $\mathrm{Fe}_{2} \mathrm{Si}$ phase formed after $1 \mathrm{~h}$ (Figure 2 and Table 2). It implies that the greater addition of $\mathrm{Si}$ inhibits the formation of the $\mathrm{Fe}_{2} \mathrm{Al}_{5}$ phase. The unreacted initial components ( $\mathrm{Al}$ and $\mathrm{Si}$ ) were found even after $2 \mathrm{~h}$ of milling together with the formed FeAl phase. Longer milling durations produced single-phase FeAl. The same conclusion was made previously during observation of the mechanism of self-propagating high-temperature 
synthesis (SHS), where the formation of the $\mathrm{Fe}_{2} \mathrm{Al}_{5}$ phase was completely suppressed by the addition of a reasonable amount of $\mathrm{Si}$ [10]. The formation of $\mathrm{Fe}_{2} \mathrm{Al}_{5}$ phase during SHS is not desirable because it generates higher porosity in Fe-Al alloys due to enormous changes in lattice parameters during the chemical reaction from pure elemental powders to $\mathrm{Fe}_{2} \mathrm{Al}_{5}$ and then to $\mathrm{FeAl}[29,31]$. The consequences of the presence of this phase in mechanical alloying are unknown. It could be expected that it causes internal porosity of the powder by the same mechanism as in reactive sintering. However, this porosity could be lowered by mechanical alloying itself (healing of internal porosity by plastic deformation) or during subsequent pressure-assisted sintering of the mechanically alloyed powder.

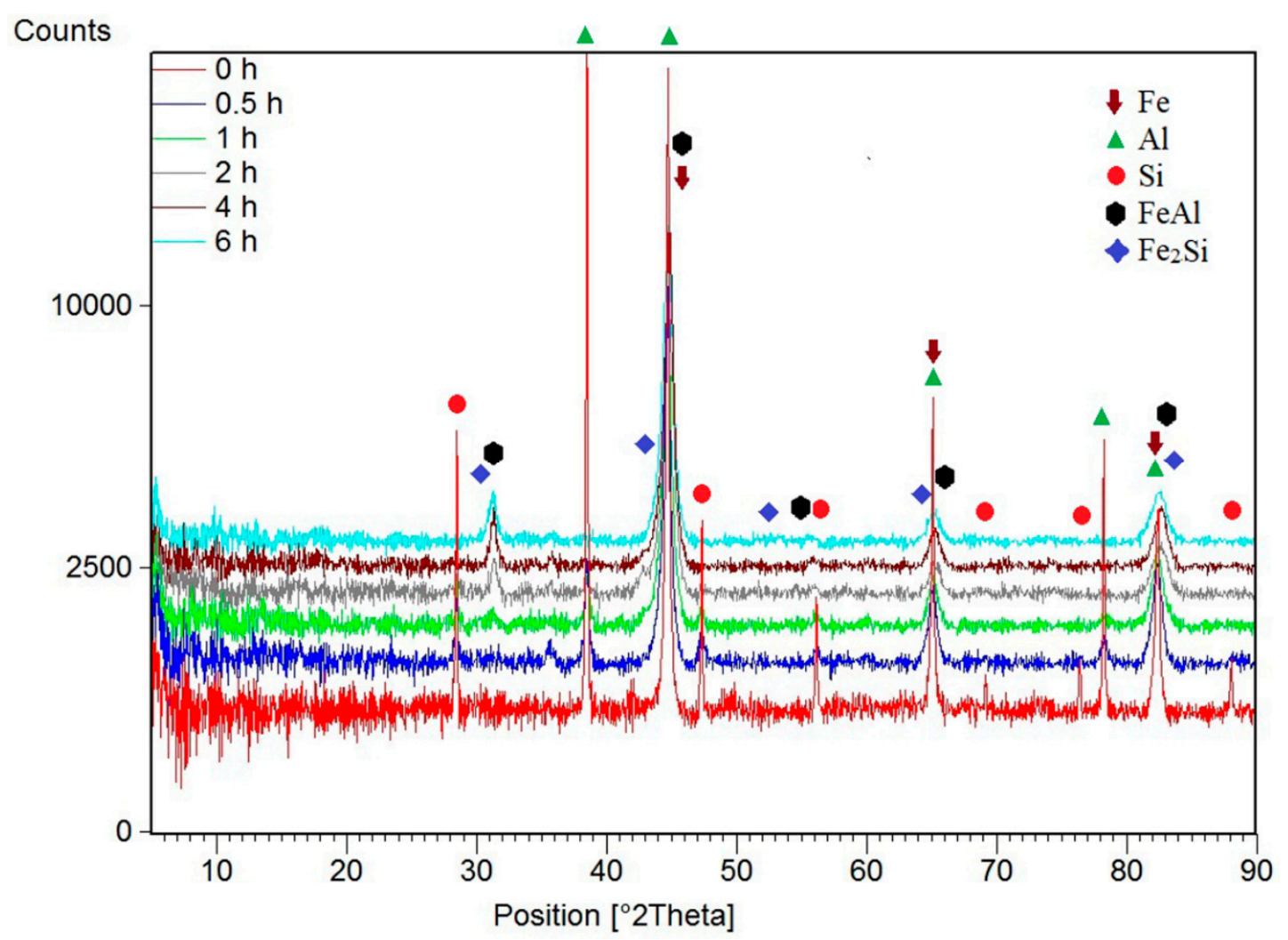

Figure 2. Phase composition of FeAl30Si10 alloy vs. milling time.

Table 2. Phase composition vs. milling time for FeAl30Si10 alloy.

\begin{tabular}{cccccc}
\hline \multirow{2}{*}{ Milling Time (h) } & \multicolumn{5}{c}{ Weight Percentage (\%) } \\
\cline { 2 - 6 } & Fe & Al & Si & FeAl & Fe $_{2} \mathbf{S i}$ \\
\hline Before MA & 60 & 30 & 10 & 0 & 0 \\
0.5 & 55 & 30 & 6 & 0 & 9 \\
1 & 0 & 12 & 9 & 74 & 5 \\
2 & 0 & 5 & 4 & 87 & 4 \\
4 & 0 & 0 & 0 & 100 & 0 \\
6 & 0 & 0 & 0 & 100 & 0 \\
\hline
\end{tabular}

In the case of FeAl20Si20 alloy, mechanical alloying for $1 \mathrm{~h}$ did not yield any intermetallics. As the process continued, the $\mathrm{Fe}_{3} \mathrm{Si}, \mathrm{FeSi}$ and $\mathrm{FeAl}$ phases were produced after $2 \mathrm{~h}$ and remained unchanged up to $6 \mathrm{~h}$ of MA. Firstly, they coexisted with unreacted Fe and Si. After $4 \mathrm{~h}$ and longer milling procedure, the unreacted components were not detected by XRD (Figure 3 and Table 3). The phase composition of FeAl20Si20 alloy powder after mechanical alloying is completely different from the Fe-Al-Si equilibrium phase diagram, where the ternary phases are expected for alloy of this composition $[32,33]$. The reason why binary phases are formed instead probably lies in the fact that the 
powders of two elements can get easily into contact during milling. In addition, mechanical alloying usually increases the mutual solubility of the elements in solid solutions, as well as in secondary solid solutions (i.e., solution of elements in an intermetallic compound) [34]. Therefore the silicides and aluminides might be substituted by $\mathrm{Al}$ and $\mathrm{Si}$, respectively. This fact was proved by the shift of diffraction lines of all phases in milled powders, as compared with the reference patterns in PDF4 database (Table 4). In the case of the FeAl phase, the shift to lower values of the lattice parameter indicates the partial substitution of $\mathrm{Al}$ and/or $\mathrm{Fe}$ by $\mathrm{Si}$, because $\mathrm{Si}$ has a lower atomic radius than both $\mathrm{Al}$ and Fe. The alloy's composition makes is likely that Si substitutes for Fe in the FeAl phase. In FeAl20Si20, the lattice parameter of the $\mathrm{Fe}_{3} \mathrm{Si}$ phase is comparable with the table value or a bit higher at certain stages of the MA process, which indicates that $\mathrm{Si}$ is probably substituted partially by $\mathrm{Al}$ with higher atomic radius than Si. However, this hypothesis cannot be verified using the applied equipment due to ultrafine microstructure of the alloys.

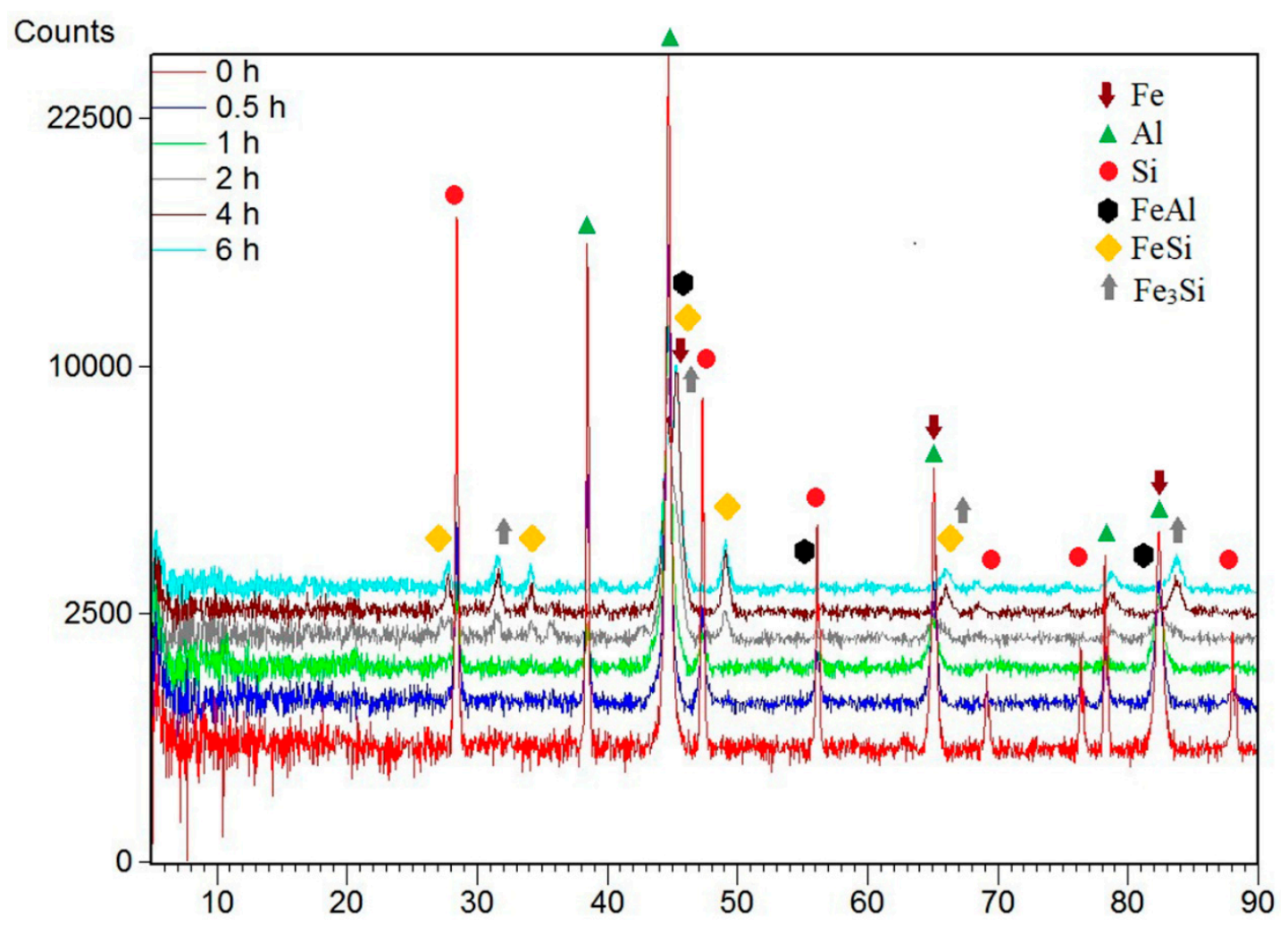

Figure 3. Phase composition of FeAl20Si20 alloy vs. milling time.

Table 3. Phase composition vs. milling time for FeAl20Si20 alloy.

\begin{tabular}{ccccccc}
\hline \multirow{2}{*}{ Milling Time (h) } & \multicolumn{6}{c}{ Weight Percentage (\%) } \\
\cline { 2 - 7 } & Fe & Al & Si & FeAl & $\mathbf{F e}_{3} \mathbf{S i}$ & FeSi \\
\hline Before MA & 60 & 20 & 20 & 0 & 0 & 0 \\
0.5 & 60 & 20 & 20 & 0 & 0 & 0 \\
1 & 75 & 4 & 21 & 0 & 5 & 0 \\
2 & 14 & 0 & 3 & 41 & 22 & 20 \\
4 & 0 & 0 & 0 & 27 & 46 & 27 \\
6 & 0 & 0 & 0 & 27 & 46 & 27 \\
\hline
\end{tabular}


Table 4. Lattice parameter $\mathrm{a}\left(\times 10^{-10} \mathrm{~m}\right)$ of the $\mathrm{FeAl}$ and $\mathrm{Fe}_{3} \mathrm{Si}$ phases vs. milling time.

\begin{tabular}{cccc}
\hline \multirow{2}{*}{ Milling Time (h) } & \multicolumn{2}{c}{ FeAl } & $\mathrm{Fe}_{3} \mathrm{Si}$ \\
\cline { 2 - 4 } & FeAl35Si5 & FeAl30Si10 & FeAl20Si20 \\
\hline Ref [35] & 2.899 & 2.899 & 5.662 \\
1 & $2.886 \pm 0.001$ & $3.095 \pm 0.001$ & - \\
2 & $2.879 \pm 0.001$ & $2.854 \pm 0.001$ & $5.671 \pm 0.001$ \\
4 & $2.885 \pm 0.001$ & $2.859 \pm 0.001$ & $5.648 \pm 0.001$ \\
6 & $2.888 \pm 0.001$ & $2.869 \pm 0.001$ & $5.663 \pm 0.001$ \\
\hline
\end{tabular}

The microstructural development of powders during mechanical alloying is presented in Figures 4-6. It is evident that after the first half hour of mechanical alloying the microstructure is composed of welded lamellae of starting powders- $\mathrm{Fe}, \mathrm{Al}$. Si is very fine because of its brittleness and it is firmly anchored between the lamellae. The phases in early stages of the process are relatively coarse and hence they can be identified by EDS analysis, see Table 5. The lamellae are mutually enriched by the other elements as a result of diffusion promoted by the temperature increase due to friction and collisions during milling. With the increasing duration of the process, the width of the lamellae decreases, and hence the diffusion path of the elements is shorter and a homogeneous structure is created as a result. The final microstructure (Figures 4,5 and $6 c, d$ ) is very fine, and therefore the EDS detector cannot be used to recognize the individual intermetallic phases. After longer process duration (Figures $4 \mathrm{~d}, 5 \mathrm{~d}$ and $6 \mathrm{~d}$ ), the contamination by chromium from the stainless steel milling vial and balls could be observed as the white particles in the powder. In Figure 4, the development of porosity is visible during longer process durations (Figure 4c,d). It confirms the above stated hypothesis that the temporary formation of $\mathrm{Fe}_{2} \mathrm{Al}_{5}$ phase and its transformation to $\mathrm{FeAl}$ phase with a totally different crystal structure causes the evolution of pores. The alloys FeAl30Si10 and FeAl20Si20 (Figures 5 and 6) tend to crack during milling due to the higher brittleness of silicon-rich phases, which appear during the process (Figures 2 and 3). The SEM images of the milled powders in Figures 4-6 also confirm that the silicon slows down the milling process because while the lamellar structure disappears completely in FeAl35Si5 and FeAl30Si10 powder blends in $2 \mathrm{~h}$ of mechanical alloying, in FeAl20Si20 the lamellar structure persists partially for up to $4 \mathrm{~h}$ of milling.

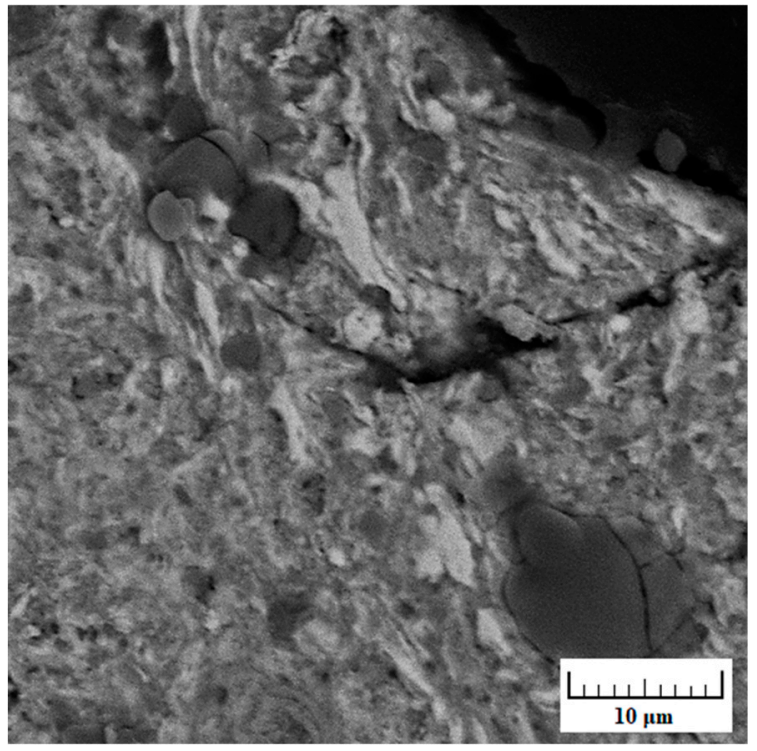

(a)

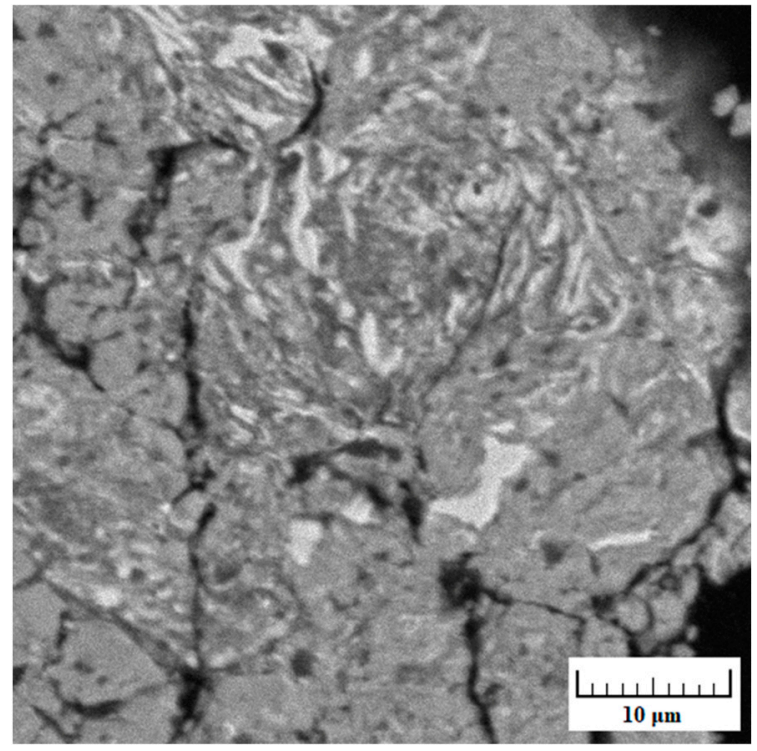

(b)

Figure 4. Cont. 


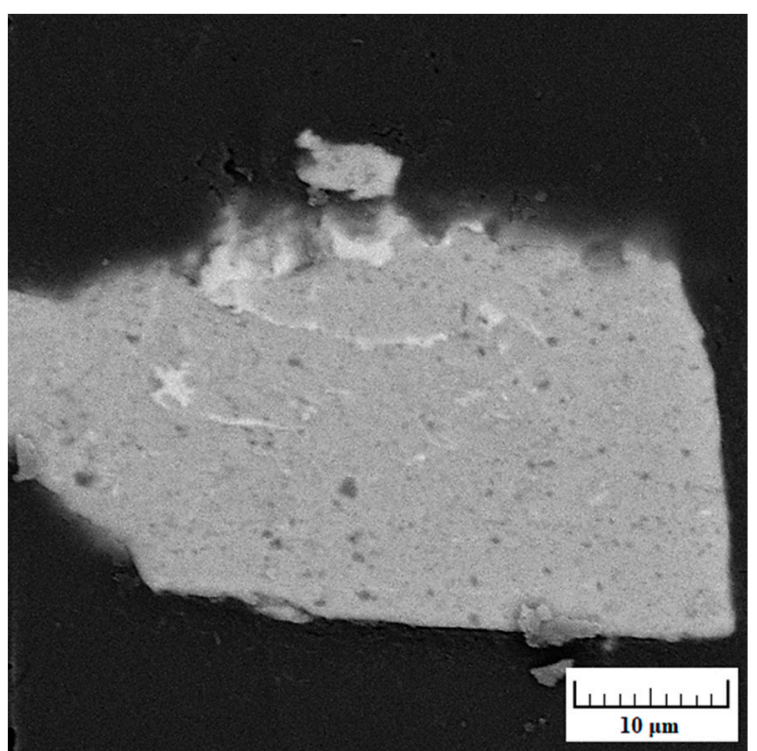

(c)

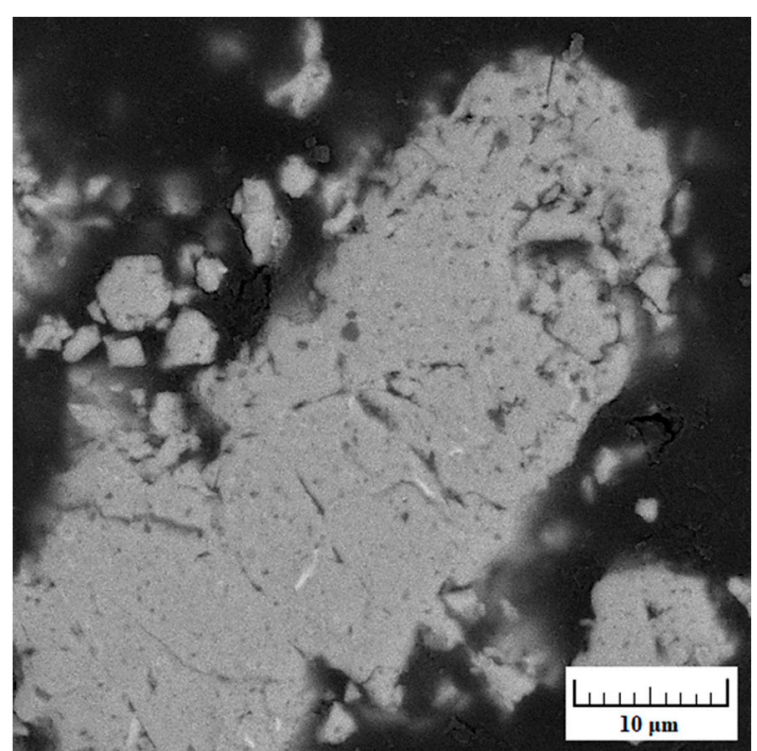

(d)

Figure 4. The SEM micrographs of the FeAl35Si5 alloy after: (a) 0.5 h, (b) 1 h, (c) 2 h, (d) 4 h of MA.

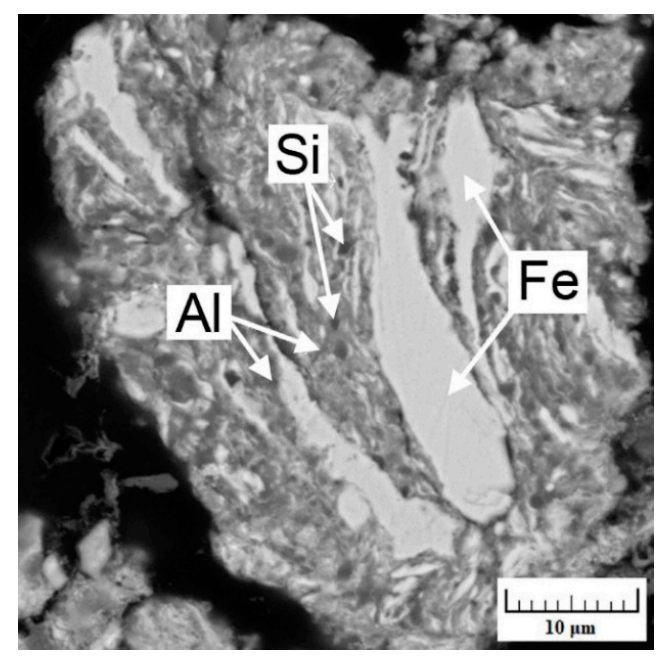

(a)

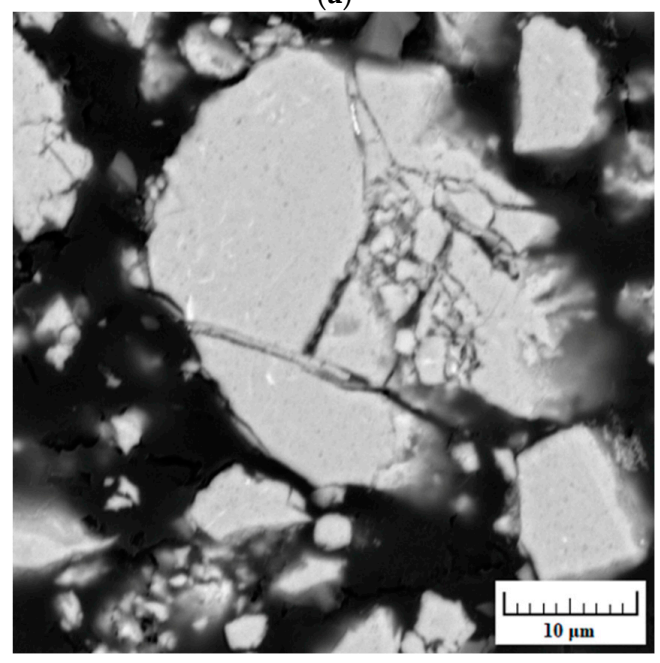

(c)

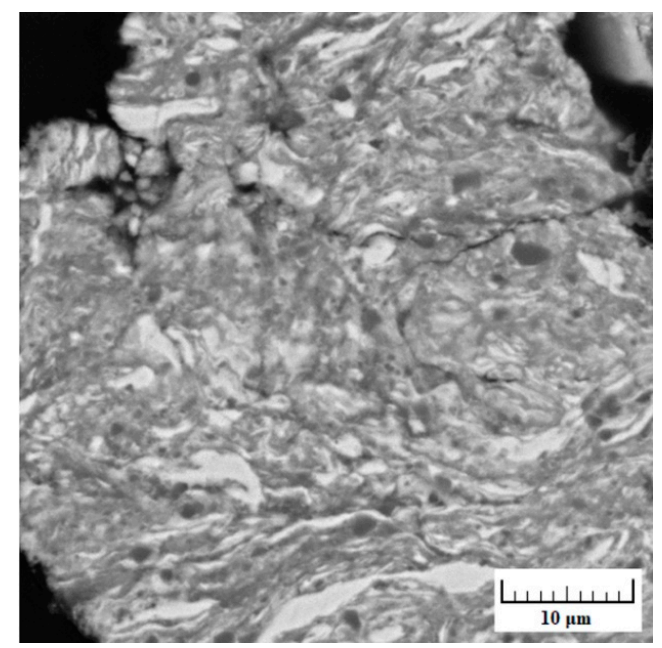

(b)

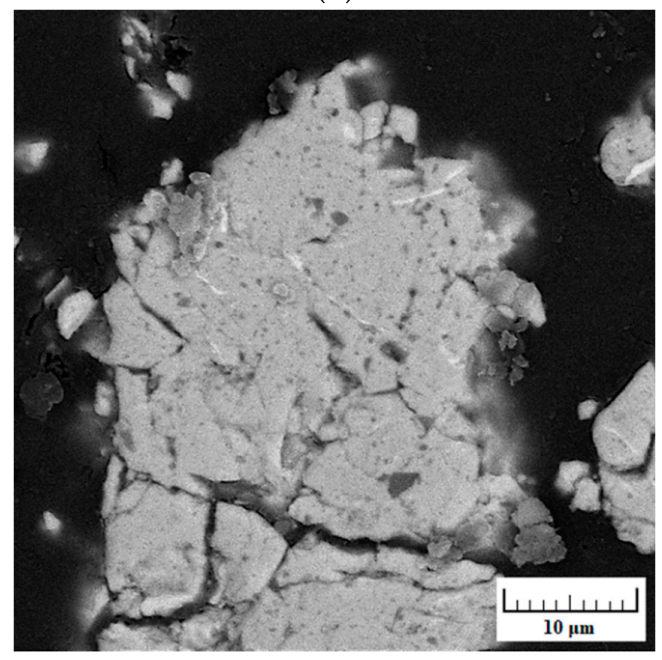

(d)

Figure 5. The SEM micrographs of the FeAl30Si10 alloy after: (a) 0.5 h, (b) 1 h, (c) 2 h, (d) 4 h of MA. 


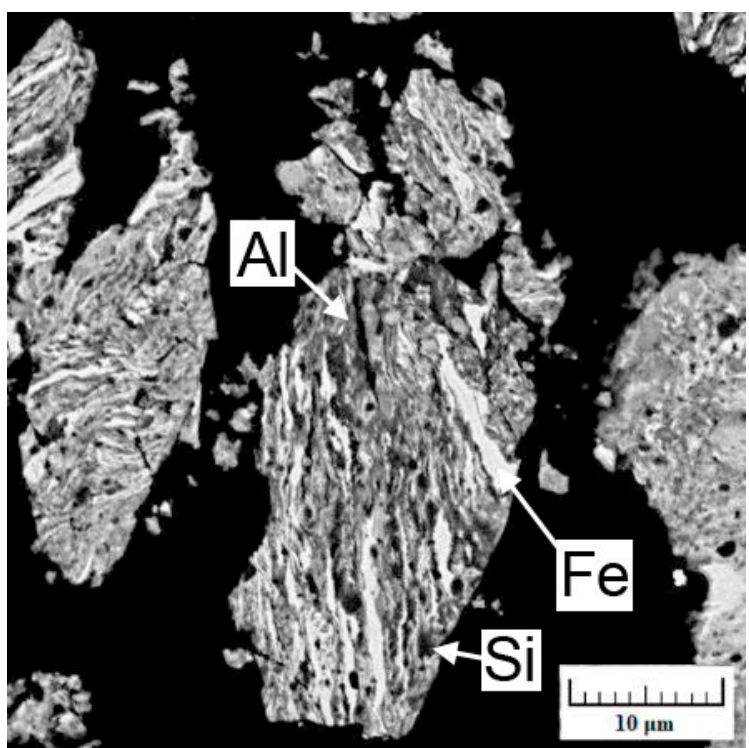

(a)

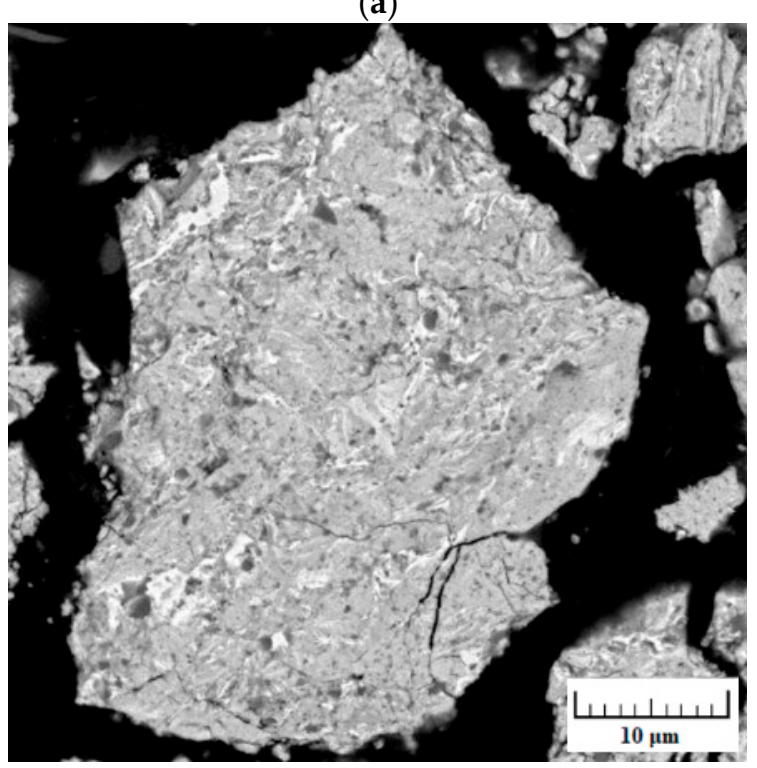

(c)

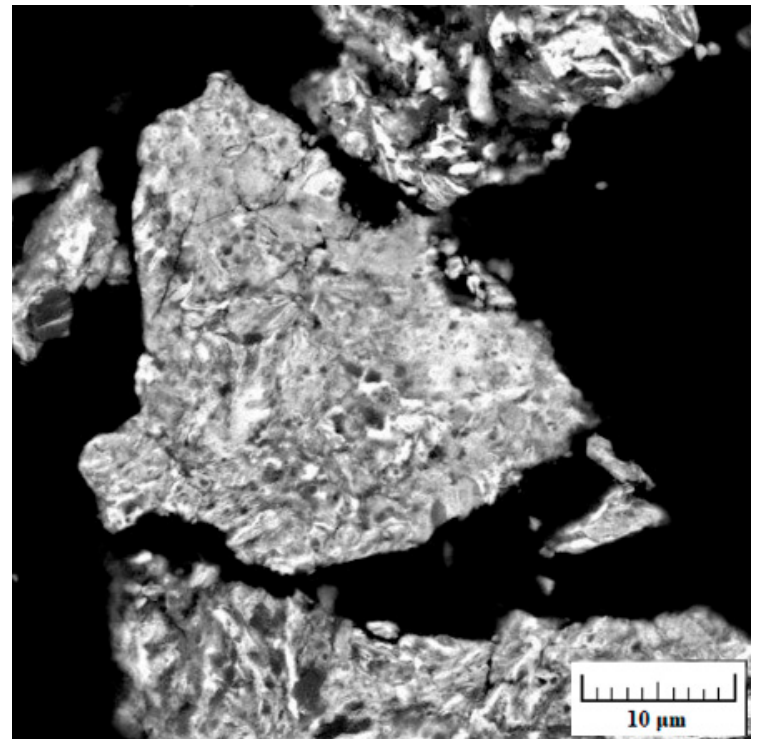

(b)

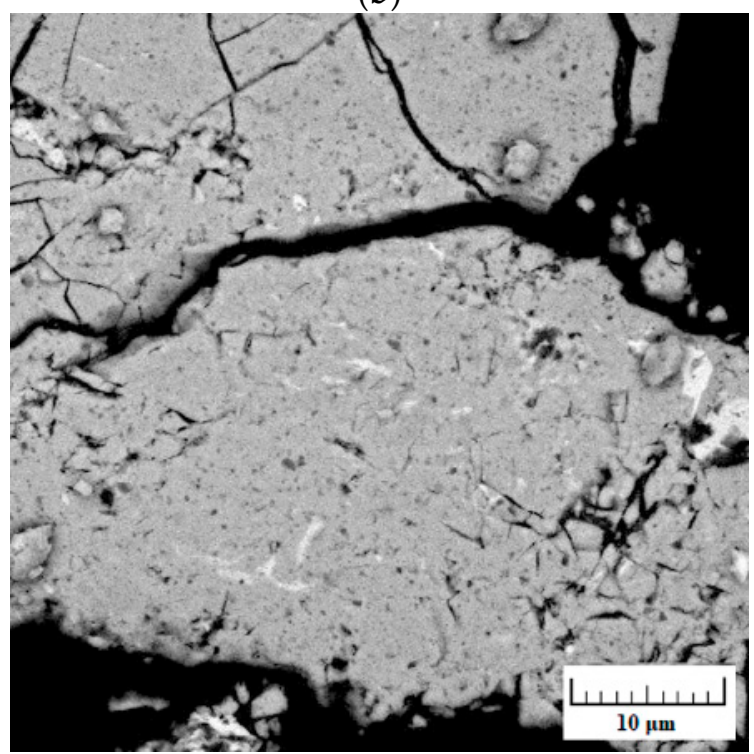

(d)

Figure 6. The SEM micrographs of the FeAl20Si20 alloy after: (a) $0.5 \mathrm{~h}$, (b) 1 h, (c) 2 h, (d) 4 h of MA.

Table 5. Average chemical composition of the phases identified in milled samples by SEM-EDS.

\begin{tabular}{cccccc}
\hline \multirow{2}{*}{$\begin{array}{c}\text { Powder } \\
\text { Mixture }\end{array}$} & \multirow{2}{*}{$\begin{array}{c}\text { Milling } \\
\text { Duration (h) }\end{array}$} & \multirow{2}{*}{$\begin{array}{c}\text { Identified } \\
\text { Phase }\end{array}$} & \multicolumn{3}{c}{ Weight Percentage (\%) } \\
\cline { 4 - 6 } & & & Fe & Al & Si \\
\hline FeAl30Si10 & 0.5 & $\mathrm{Fe}$ & $87.7 \pm 1.6$ & $9.8 \pm 0.8$ & $2.5 \pm 0.8$ \\
FeAl30Si10 & 0.5 & $\mathrm{Al}$ & $15.6 \pm 1.8$ & $67.1 \pm 3.5$ & $17.3 \pm 1.7$ \\
FeAl30Si10 & 0.5 & $\mathrm{Si}$ & $4.1 \pm 1.2$ & 0 & $95.9 \pm 1.2$ \\
FeAl20Si20 & 0.5 & $\mathrm{Fe}$ & $87.0 \pm 1.0$ & $10.0 \pm 0.5$ & $3.0 \pm 0.5$ \\
FeAl20Si20 & 0.5 & $\mathrm{Al}$ & $6.7 \pm 1.0$ & $69.4 \pm 2.0$ & $23.9 \pm 1.0$ \\
FeAl20Si20 & 0.5 & $\mathrm{Si}$ & $17.1 \pm 0.5$ & $18.5 \pm 0.5$ & $64.3 \pm 1.0$ \\
\hline
\end{tabular}

The crystallite size determined by XRD and calculated by Rietveld method showed that the structure of all elemental powders ( $\mathrm{Fe}, \mathrm{Al}, \mathrm{Si}$ ) has been significantly refined at the very beginning of mechanical alloying. Once the intermetallics are formed their crystallite size is then almost independent of the milling duration, reaching $10-20 \mathrm{~nm}$ (see Figure $7 \mathrm{a}-\mathrm{c}$ ). The crystallite size of the transient $\mathrm{Fe}_{2} \mathrm{Al}_{5}$ phase is a bit higher than the one of FeAl phase. The reason for that is probably the fact 
that $\mathrm{Fe}_{2} \mathrm{Al}_{5}$ phase exhibits almost no plasticity in contrast to $\mathrm{B} 2 \mathrm{FeAl}$ phase. Due to plasticity, the grain refinement by severe plastic deformation during milling could occur, leading to finer structure. The same trend is observable for iron silicides, where lower ductility could also be expected when the content of $\mathrm{Si}$ in the compound increases. However, the trend is less significant, probably due to the generally lower plasticity of silicides than aluminides.

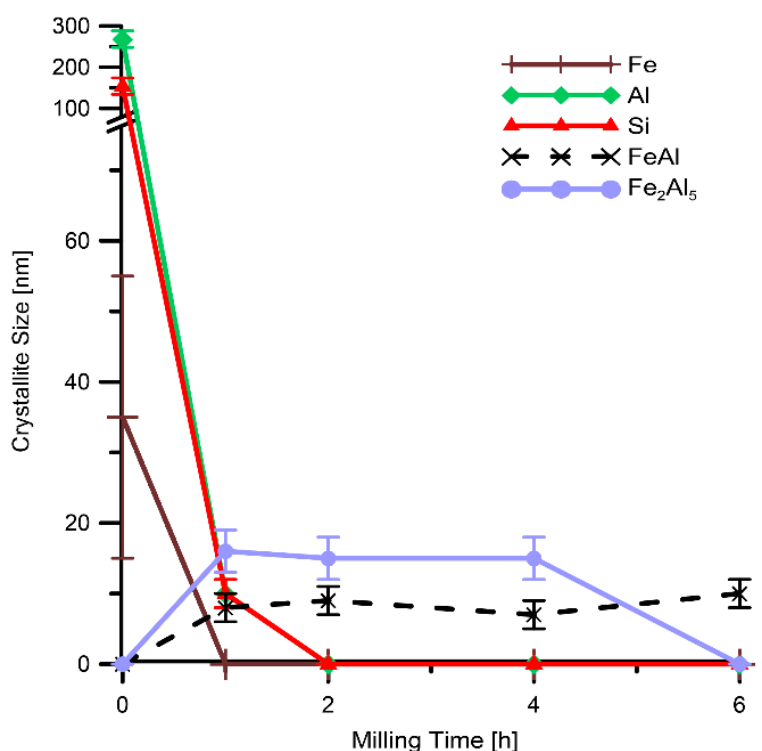

(a)

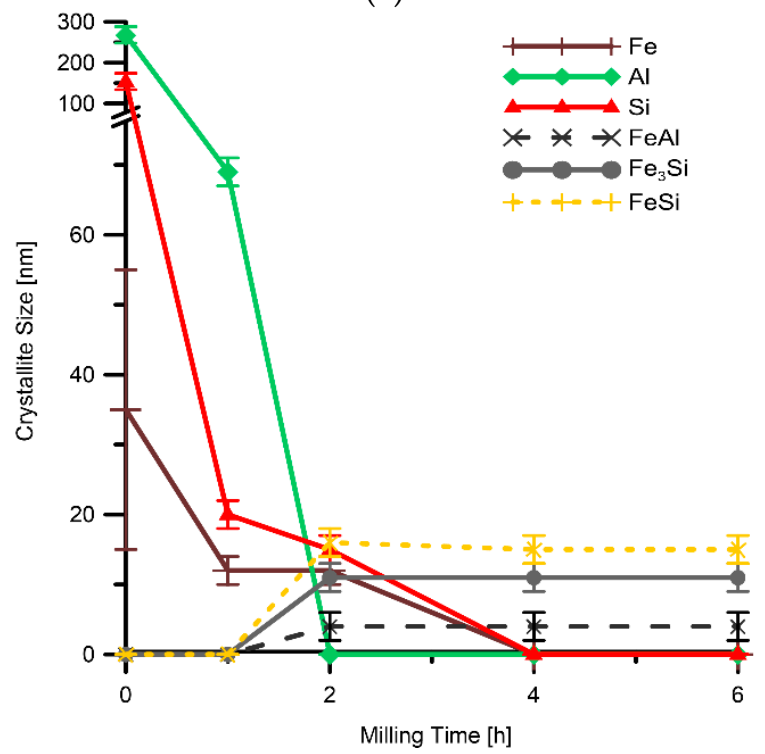

(c)

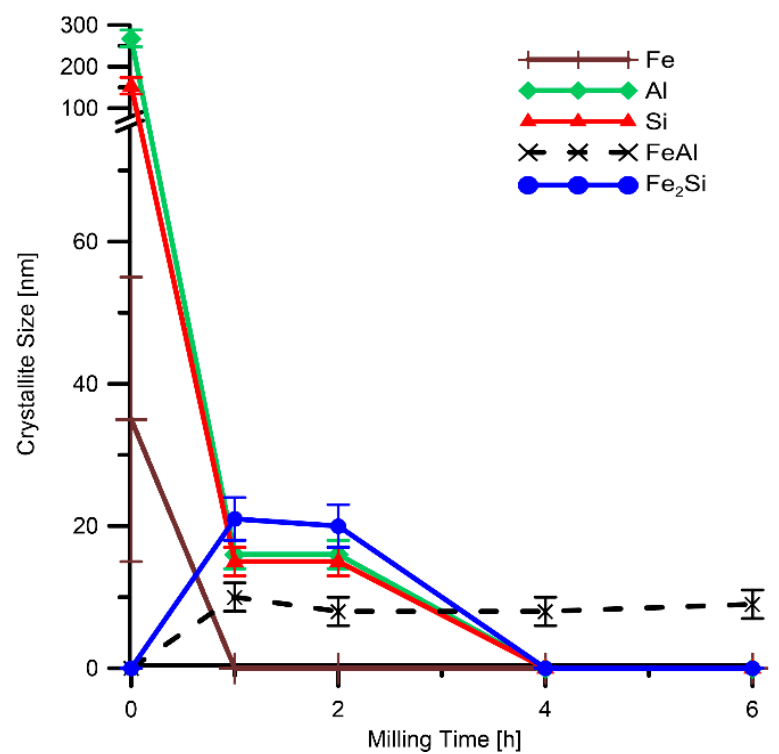

(b)

Figure 7. Crystallite size vs. milling time for: (a) FeAl35Si5, (b) FeAl30Si10 and (c) FeAl20Si20 alloy.

The average particle size of powders before milling is presented in Figure 8 . Between 0 and $2 \mathrm{~h}$ an increase in the particle size occurred, followed by a decrease of the particle size due to two contradictory processes. The formation of cold welds between particles led to an increase in particle size, while the cracking of powder particles is caused by deformation strengthening. Between 2 and $4 \mathrm{~h}$ of mechanical alloying, the size of the powder particles decreased because of cracking as a result of the formation of brittle intermetallic phases and continual deformation of powders. After exceeding $4 \mathrm{~h}$ of milling, the particle size remained almost constant, showing a balance between continual cracking and cold welding. 


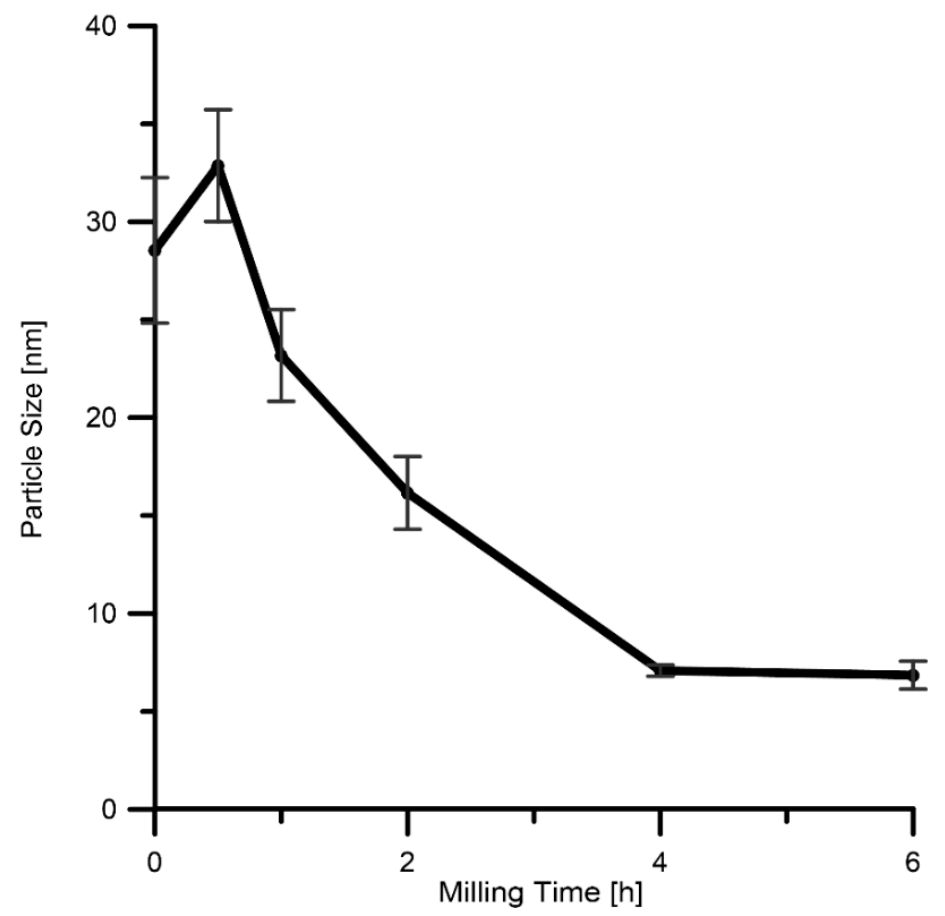

Figure 8. Powder particle size vs. milling time for alloy FeAl20Si20.

In order to determine the thermal stability of the mechanically alloyed powders and to predict the subsequent sintering behavior, DTA of the milled powders has been carried out. Using the DTA analysis, the possible problems during sintering, such as phase transformations which could cause the volume changes, the appearance of unwanted phases with undesirable properties or partial melting of the alloy due to the existence of metastable lower-melting phases could be predicted. These results have general validity for the optimization of further consolidation by any method including spark plasma sintering, hot isostatic pressing or even free sintering. The heating curves presented in Figure 9 exhibit weak exothermic effects at approx. $500-630^{\circ} \mathrm{C}$ and $800-1050^{\circ} \mathrm{C}$ depending on the powder composition. Therefore, the powders of all alloys after mechanical alloying were annealed at 630 and $1030^{\circ} \mathrm{C}$ in order to explain the observed thermal effects. It was found that the reaction below $630{ }^{\circ} \mathrm{C}$ is associated with the formation of $\mathrm{Fe}_{2} \mathrm{Al}_{5}$ phase (Table 6). This intermetallic compound probably formed because of the depletion of the silicides by $\mathrm{Al}$ during annealing. As stated above, the binary silicides and aluminides are supersaturated by $\mathrm{Al}$ and $\mathrm{Si}$, respectively. This depletion could lead to the formation of another aluminide phase, which has been previously determined as a typical product of a direct reaction of iron with $\mathrm{Al}$ [29]. On the other hand, the reactions at the temperatures close to $1030{ }^{\circ} \mathrm{C}$ are connected with the formation of $\mathrm{Fe}_{3} \mathrm{Si}$ silicide in FeAl35Si5 and FeAl30Si10 alloys, probably due to the $\mathrm{Si}$ escape from the aluminide phase. In the case of the FeAl20Si20 alloy, ternary phase $\mathrm{Fe}_{2} \mathrm{Al}_{3} \mathrm{Si}_{3}$ forms in the powder during annealing at $1030{ }^{\circ} \mathrm{C}$. From these findings, it can be predicted that the porosity will be formed if free sintering would be applied due to the transient $\mathrm{Fe}_{2} \mathrm{Al}_{5}$ phase, which has a big misfit of lattice parameters with the other $\mathrm{Fe}-\mathrm{Al}$ and Fe-Si phases [36]. The pressure-assisted sintering, such as hot isostatic pressing or spark plasma sintering can be highly recommended. The highly brittle behavior could be expected in the case of the FeAl20Si20 alloy due to the presence of Fe-Al-Si ternary phase in the compact. 


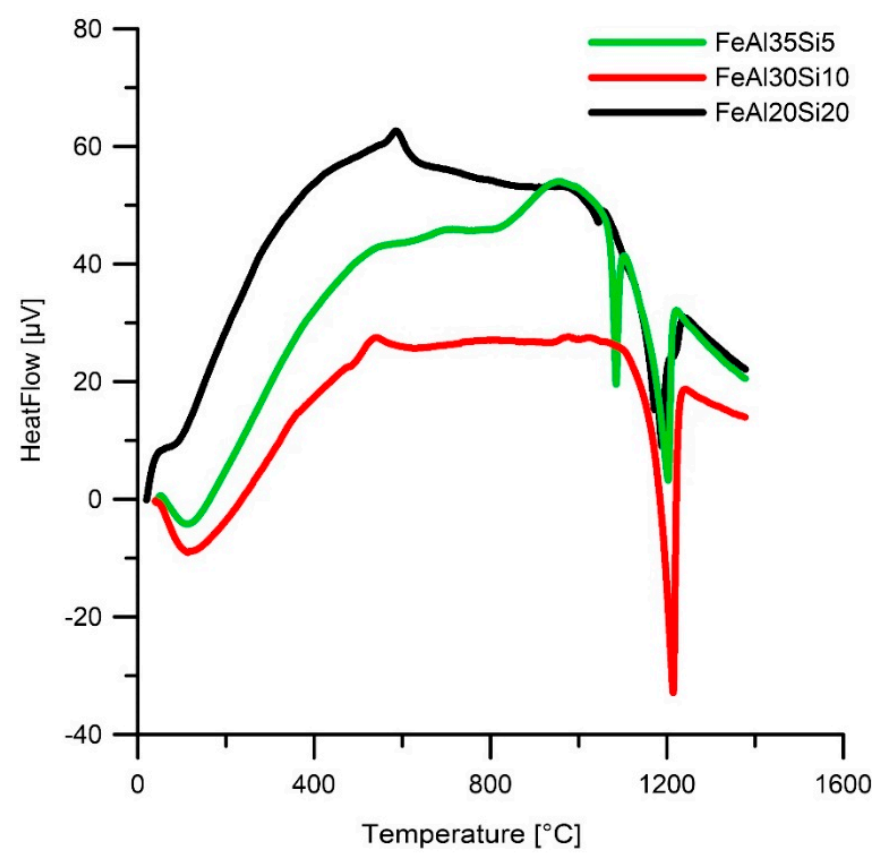

Figure 9. DTA heating curve of MA $(4 \mathrm{~h})$ sample depending on the chemical composition of powder.

Table 6. Phase composition of the powders vs. annealing temperature and alloy composition.

\begin{tabular}{|c|c|c|c|c|c|c|}
\hline \multirow{2}{*}{$\begin{array}{c}\text { Annealing } \\
\text { Temperature }\left({ }^{\circ} \mathrm{C}\right)\end{array}$} & \multirow{2}{*}{ Alloy Composition } & \multicolumn{5}{|c|}{ Weight Percentage (\%) } \\
\hline & & FeAl & $\mathrm{Fe}_{3} \mathrm{Si}$ & $\mathrm{Fe}_{2} \mathrm{Al}_{5}$ & $\mathrm{FeSi}$ & $\mathrm{Fe}_{2} \mathrm{Al}_{3} \mathrm{Si}_{3}$ \\
\hline $630^{\circ} \mathrm{C}$ & FeAl35Si5 & 91 & - & 9 & - & - \\
\hline $630^{\circ} \mathrm{C}$ & FeAl30Si10 & 95 & - & 5 & - & - \\
\hline $630^{\circ} \mathrm{C}$ & FeAl20Si20 & 25 & 44 & 4 & 27 & - \\
\hline $1030^{\circ} \mathrm{C}$ & FeAl35Si5 & 86 & 5 & 9 & - & - \\
\hline $1030^{\circ} \mathrm{C}$ & FeAl30Si10 & 90 & 8 & 5 & - & - \\
\hline $1030^{\circ} \mathrm{C}$ & FeAl20Si20 & 25 & 45 & 0 & 20 & 10 \\
\hline
\end{tabular}

\section{Conclusions}

In this work, the dependence of the phase composition on the duration of ultra-high energy mechanical alloying was studied. It was found that the powders of low-silicon alloys (up to $10 \mathrm{wt}$. \%) consist of FeAl phase supersaturated by Si after mechanical alloying. The alloy containing $20 \mathrm{wt}$. \% of $\mathrm{Si}$ and $20 \mathrm{wt}$. \% of $\mathrm{Al}$ is composed mostly of iron silicides $\left(\mathrm{Fe}_{3} \mathrm{Si}\right.$ and $\left.\mathrm{FeSi}\right)$ and $\mathrm{FeAl}$ ordered phase. Increasing the content of Si lowers the rate of phases' formation during MA. The higher the Si content, the longer the time required for the full transformation of the reagents to the products. In addition, a Si amount of $10 \mathrm{wt}$. \% or higher suppresses the formation of transient $\mathrm{Fe}_{2} \mathrm{Al}_{5}$ phase during the MA process. During annealing of the mechanically alloyed powders, which was used in order to predict the sintering behavior, the $\mathrm{Fe}_{2} \mathrm{Al}_{5}$ forms at around $600^{\circ} \mathrm{C}$. At temperatures around $1000{ }^{\circ} \mathrm{C}$, the silicide $\left(\mathrm{Fe}_{3} \mathrm{Si}\right)$ or ternary phase $\left(\mathrm{Fe}_{2} \mathrm{Al}_{3} \mathrm{Si}_{3}\right)$ forms depending on the alloy composition. It indicates that the mechanically alloyed powders have a highly metastable phase composition and significant changes can be expected during the subsequent sintering.

Author Contributions: K.N. coordinated the work, compiled the paper and realized the mechanical alloying procedure. P.N. worked as a scientific supervisor and ensured an evaluation of DTA results. F.P. and J.C. realized the SEM observation. J.K. evaluated the XRD results.

Funding: This research was funded by Grantová Agentura České Republiky, grant number 17-07559S, Ministerstvo Školství, Mládeže a Tělovýchovy, projects 21-SVV/2018 and SAFMAT CZ.02.1.01/0.0/0.0/16_013/ 0001406. The APC was funded by Ministerstvo Školství, Mládeže a Tělovýchovy, project SAFMAT CZ.02.1.01/0.0/0.0/16_013/0001406. 
Acknowledgments: This research was financially supported by Czech Science Foundation, project No. 17-07559S and MŠMT No. 21-SVV/2018. This work was also supported in part by the MEYS SAFMAT CZ.02.1.01/0.0/0.0/16_013/0001406.

Conflicts of Interest: The authors declare no conflict of interest. The funders had no role in the design of the study; in the collection, analyses, or interpretation of data; in the writing of the manuscript, and in the decision to publish the results.

\section{References}

1. McKamey, C.G.; DeVan, J.H.; Tortorelli, P.F.; Sikka, V.K. A review of recent developments in Fe3Al-based alloys. J. Mater. Res. 2011, 6, 1779-1805. [CrossRef]

2. Stoloff, N.S. Iron aluminides: Present status and future prospects. Mater. Sci. Eng. A 1998, 258, 1-14. [CrossRef]

3. Talischi, L.A.; Samadi, A. Structural characterization and ordering transformation of mechanically alloyed nanocrystalline Fe-28Al powder. J. Ultrafine Grained Nanostruct. Mater. 2016, 49, 112-119.

4. Novák, P.; Kř́̌ž, J.; Michalcová, A.; Vojtěch, D. Microstructure evolution of Fe-Al-Si and Ti-Al-Si alloys during high-temperature oxidation. Mater. Sci. Forum 2014, 782, 353-358. [CrossRef]

5. Couperthwaite, R.A.; Cornish, L.A.; Mwamba, I.A.; Papo, M.J. Effect of processing route on the microstructure and properties of an Fe-Al alloy with additions of precious metal. Mater. Today Proc. 2015, 2, 3932-3942. [CrossRef]

6. Deevi, S.C.; Sikka, V.K.; Liu, C.T. Processing, properties, and applications of nickel and iron aluminides. Prog. Mater. Sci. 1997, 42, 177-192. [CrossRef]

7. Marker, M.C.J.; Skolyszewska-Kühberger, B.; Effenberger, H.S.; Schmetterer, C.; Richter, K.W. Phase equilibria and structural investigations in the system Al-Fe-Si. Intermetallics 2011, 19, 1919-1929. [CrossRef]

8. Š́koláková, A.; Novák, P.; Vojtěch, D.; Kubatík, T.F. Microstructure and mechanical properties of Al-Si-Fe-X. alloys. Mater. Des. 2016, 107, 491-502. [CrossRef]

9. Li, H.; Zhang, J.; Young, D.J. Oxidation of $\mathrm{Fe}-\mathrm{Si}, \mathrm{Fe}-\mathrm{Al}$ and $\mathrm{Fe}-\mathrm{Si}-\mathrm{Al}$ alloys in $\mathrm{Co}_{2}-\mathrm{H}_{2} \mathrm{O}$ gas at $800{ }^{\circ} \mathrm{C}$. Corros. Sci. 2012, 54, 127-138. [CrossRef]

10. Novák, P.; Zelinková, M.; Šerák, J.; Michalcová, A.; Novák, M.; Vojtěch, D. Oxidation resistance of SHS $\mathrm{Fe}-\mathrm{Al}-\mathrm{Si}$ alloys at $800^{\circ} \mathrm{C}$ in air. Intermetallics 2011, 19, 1306-1312. [CrossRef]

11. Shen, C.; Pan, Z.; Cuiuri, D.; Ding, D.; Li, H. Influences of deposition current and interpass temperature to the Fe3Al-based iron aluminide fabricated using wire-arc additive manufacturing process. Int. J. Adv. Manuf. Technol. 2017, 88, 2009-2018. [CrossRef]

12. Satya Prasad, V.V.; Khaple, S.; Baligidad, R.G. Melting, processing, and properties of disordered Fe-Al and Fe-Al-C based alloys. J. Miner. Met. Mater. Soc. 2014, 66, 1785-1793. [CrossRef]

13. Sundar, R.S.; Baligidad, R.G.; Prasad, Y.V.R.K.; Sastry, D.H. Processing of iron aluminides. Mater. Sci. Eng. A 1998, 258, 219-228. [CrossRef]

14. Song, H.; Wu, Y.; Tang, C.; Yuan, S.; Gong, Q.; Liang, J. Microstructure and mechanical properties of FeAl intermetallics prepared by mechanical alloying and hot-pressing. Tsinghua Sci. Technol. 2009, 14, 300-306. [CrossRef]

15. Krasnowski, M.; Kulik, T. Nanocrystalline FeAl intermetallic produced by mechanical alloying followed by hot-pressing consolidation. Intermetallics 2007, 15, 201-205. [CrossRef]

16. Novák, P.; Moravec, H.; Vojtěch, V.; Kopeček, J. Powder-metallurgy preparation of Ni-Ti shape-memory alloy using mechanical alloying and spark plasma sintering. Mater. Technol. 2017, 51, 141-144.

17. Suryanarayana, C. Mechanical alloying and milling. Prog. Mater. Sci. 2001, 46, 1-184. [CrossRef]

18. Enayati, M.H.; Mohamed, F.A. Application of mechanical alloying/milling for synthesis of nanocrystalline and amorphous materials. Int. Mater. Rev. 2014, 59, 394-416. [CrossRef]

19. Novák, P.; Průša, F.; Nová, K.; Bernatiková, A.; Salvetr, P.; Kopeček, J.; Haušild, P. Application of mechanical alloying in synthesis of intermetallics. Acta Phys. Pol. A 2018, 134, 720-723. [CrossRef]

20. Shi, H.; Guo, D.; Ouyang, Y. Structural evolution of mechanically alloyed nanocrystalline FeAl intermetallics. J. Alloys Compd. 2008, 455, 207-209. [CrossRef]

21. Krasnowski, M.; Grabias, A.; Kulik, T. Phase transformations during mechanical alloying of $\mathrm{Fe}-50 \% \mathrm{Al}$ and subsequent heating of the milling product. J. Alloys Compd. 2006, 424, 119-127. [CrossRef] 
22. Haghighi, S.E.; Janghorban, K.; Izadi, S. Structural evolution of $\mathrm{Fe}-50$ at $\% \mathrm{Al}$ powders during mechanical alloying and subsequent annealing processes. J. Alloys Compd. 2010, 495, 260-264. [CrossRef]

23. Enayati, M.H.; Salehi, M. Formation mechanism of Fe3Al and FeAl intermetallic compounds during mechanical alloying. J. Mater. Sci. 2005, 40, 3933-3938. [CrossRef]

24. Zoz, H.; Reichardt, R.; Ren, H. Energy balance during mechanical alloying, measurement and calculation method supported by the Maltoz®-software. Adv. Powder Metall. Part. Mater. 1999, 1, 1-109.

25. Abdellaoui, M.; Gaffet, E. The physics of mechanical alloying in a planetary ball mill: Mathematical treatment. Acta Metall. Mater. 1995, 43, 1087-1098. [CrossRef]

26. Shelekhov, E.V.; Tcherdyntsev, V.V.; Pustov, L.Y.; Kaloshkin, S.D.; Tomilin, I.A. Calculation of energy intensity and temperature of mechanoactivation process in planetary ball mill by computer simulation. In Investigations and Applications of Severe Plastic Deformation; Lowe, T.C., Valiev, R.Z., Eds.; Springer Netherlands: Dordrecht, The Netherlands, 2000; pp. 139-145.

27. Prică, C.-V.; Marinca, T.F.; Popa, F.; Sechel, N.A.; Isnard, O.; Chicinaş, I. Synthesis of nanocrystalline Ni3Fe powder by mechanical alloying using an extreme friction mode. Adv. Powder Technol. 2016, 27, $395-402$. [CrossRef]

28. Bernatiková, A.; Novák, P.; Průša, F. Preparation of Ti-Al and Fe-Al alloys by mechanical alloying. Acta Phys. Pol. A 2018, 134, 733-737. [CrossRef]

29. Novák, P.; Michalcová, A.; Marek, I.; Mudrová, M.; Saksl, K.; Bednarčík, J.; Zikmund, P.; Vojtěch, D. On the formation of intermetallics in Fe-Al system-an in situ XRD study. Intermetallics 2013, 32, 127-136. [CrossRef]

30. Song, J.L.; Lin, S.B.; Yang, C.L.; Ma, G.C.; Liu, H. Spreading behavior and microstructure characteristics of dissimilar metals TIG welding-brazing of aluminum alloy to stainless steel. Mater. Sci. Eng. A 2009, 509, 31-40. [CrossRef]

31. Jóźwiak, S.; Karczewski, K.; Bojar, Z. Kinetics of reactions in FeAl synthesis studied by the DTA technique and JMA model. Intermetallics 2010, 18, 1332-1337. [CrossRef]

32. Liu, Z.-K.; Chang, Y.A. Thermodynamic assessment of the Al-Fe-Si system. Metall. Mater. Trans. A 1999, 30, 1081-1095. [CrossRef]

33. Effenberg, G. Ternary Alloy Systems-Phase Diagrams, Crystallographic and Thermodynamic Data: Light Metal Systems, Part 2: Selected Systems From Al-Cu-Fe to Al-Fe-Ti; Landolt-Börnstein: Stuttgart, Germany, 2005.

34. Huang, B.L.; Perez, R.J.; Lavernia, E.J.; Luton, M.J. Formation of supersaturated solid solutions by mechanical alloying. Nanostruct. Mater. 1996, 7, 67-79. [CrossRef]

35. Kabekkodu, S. ICCD 2018 Powder Diffraction File; International Centre for Diffraction Data: 12 Campus Boulevard, Newton Square, PA, USA.

36. Kang, H.Z.; Hu, C.T. Swelling behavior in reactive sintering of Fe-Al mixtures. Mater. Chem. Phys. 2004, 88, 264-272. [CrossRef]

(C) 2018 by the authors. Licensee MDPI, Basel, Switzerland. This article is an open access article distributed under the terms and conditions of the Creative Commons Attribution (CC BY) license (http://creativecommons.org/licenses/by/4.0/). 